\title{
PREPARATION AND CHARACTERIZATION OF MICROFILTRATION CERAMIC MEMBRANE FOR OILY WASTE WATER TREATMENT
}

\author{
Sandeep Parma ${ }^{1}$, Pradip Chowdhury ${ }^{2}$ \\ ${ }^{1}$ Department of Chemical Engineering, Manipal Institute of Technology, Manipal University Manipal 576104, Karnataka, \\ India \\ ${ }^{2}$ Department of Chemical Engineering, Manipal Institute of Technology, Manipal University Manipal 576104, Karnataka, \\ India
}

\begin{abstract}
This work highlights the preparation of ceramic membranes from a low-cost naturally occurring clay material viz. red mud. Additives like sodium carbonate, sodium metasilicate and boric acid was added in standard stoichiometric ratio with the processed clay material, imparting characteristic properties. Paste casting method was followed for fabricating circular disc shaped membranes with $50 \mathrm{~mm} \times 5 \mathrm{~mm}$ dimensions. Sintering effects were studied by exposing the membranes at temperatures ranging between $500^{\circ} \mathrm{C}$ to $800^{\circ} \mathrm{C}$ in a programmable muffle furnace. The membranes fabricated were characterized using standard characterization techniques like Scanning Electron Microscopy (SEM) and Powder X-ray Diffraction Analysis (PXRD). Finally, water permeation studies were carried out in a standard membrane module within the microfiltration regime i.e. $<5 \mathrm{~kg} \mathrm{~cm}^{-2}$, obtaining a standard permeation flux and the data was used in calculating the porosity of the ceramic membrane. These membranes were found well suited for oily waste water studies. A maximum rejection of $53 \%$ was achieved with membrane sintered at $800^{\circ} \mathrm{C}$.
\end{abstract}

Keywords: Ceramic Membrane, Red Mud, Microfiltration, Flux

\section{INTRODUCTION}

The applications of ceramic membrane have increased due to its excellent thermal, chemical and mechanical stability and higher separation efficiency[1]. In near future, the emergence of new type of ceramic materials and simple fabrication techniques may lead to preparation of low cost ceramic microfiltration membranes. The applications of alumina-based ceramic membranes are limited due to high cost and sintering temperature. Therefore, the natural clay based low cost ceramic membranes would be an attractive proposition. Many researchers have already used low cost clays such as raw clay, Moroccan[2] clay[3], tunisian clay[4], sepiolite clay, algerian clay[9], dolomite and kaolin for membrane fabrication. Kaolin is one of the cheapest membrane raw materials easily available in India. Various researchers have reported the use of kaolin and natural clay as a starting material with other additives for membrane physical applications.

Early research in inorganic membrane fabrication is focused towards the utilization of $\alpha$-alumina which is an expensive precursor to fabricate the membrane [2] . Research at a later stage, involved the utilization of inorganic materials such as $\gamma$ alumina [8], zirconia titania and silica [6]. Nonetheless, the cost of these precursors remains to be significantly high and therefore significantly contributes to the operating cost of membrane modules for industrial applications. To circumvent the issue of membrane cost, recent research in the fabrication of inorganic membranes is focused towards the utilization of cheaper raw materials such as apatite powder [15], fly ash [5], natural raw clay [12], dolomite, kaolin [10]. Of these inorganic precursors, kaolin appears to be an important inexpensive raw material that can be studied for the fabrication of stable microfiltration range inorganic membranes at a lesser cost. Potdar et al. and Neelakandan et al. have provided optimal inorganic formulations (based on dry basis) using kaolin (12.7 wt.\%), ball clay (16.1 wt.\%), quartz (23.6 wt.\%), feldspar (5.1 wt.\%), CaCO3 (28.1 wt.\%) and pyrophallite (14.3 wt.\%) for the fabrication of micro-filtration range inorganic membranes. Of these precursors, quartz, feldspar and pyrophallite could be regarded as expensive materials when compared to kaolin, ball clay and calcium carbonate. In a similar approach, Belouatek et al. have reported optimal inorganic formulations (based on dry basis) using clay (21 wt.\%), kaolin (35 wt.\%), feldspar (20 wt.\%) and sand (24 wt.\%) for fabricating inorganic supports capable for liquid waste treatment. Incidentally, the sintering temperature of this work is about $1100{ }^{\circ} \mathrm{C}$. Of these ingredients reported by the authors, only feldspar can be regarded as an expensive raw material compared to the others i.e., clay, kaolin and sand

A large quantity of oily wastewater is generated from various process industries: particularly from refineries and metallurgical plants. It is highly essential to separate the oily component before being discharged into a municipal sewage system to protect the environment by maintaining government 
regulations. Additionally, it might yield some value added product. Conventional methodologies like skimming, gravity settling etc. take longer time between batches, requires large spaces and higher logistical supports. Membrane technology on the other hand follows a compact design and relatively low operational costs.

\section{EXPERIMENTAL WORKS}

\subsection{Raw Materials}

Clay: Take raw muddy clay from MIT Manipal campus dry the clay at $80{ }^{\circ} \mathrm{C}$, it was ground in a ball mill and passed through $300 \mu$ mesh screen. All the membranes were prepared with $300 \mu$ mesh clay powder. The major constituents of clay is from literature, silica in the form of silicon dioxide $\left(\mathrm{SiO}_{2}\right)$, aluminium as aluminium oxide $\left(\mathrm{Al}_{2} \mathrm{O}_{3}\right)$ and sodium as sodium oxide $\left(\mathrm{Na}_{2} \mathrm{O}\right)$.

Chemicals: Sodium metasilicate, sodium carbonate and boric acid were used for membrane preparation as a additives . Sodium metasilicate increases mechanical strength by creating silicate bonds. Sodium carbonate improves dispersion properties of a membrane, thereby creating homogeneity. Boric acid also increases mechanical strength by creating metaborates during sintering.

\subsection{Fabrication of Membrane}

The membranes were prepared by paste casting from the compositions given in Table 1 . The materials were mixed with distilled water and the paste was casted over a aluminium foil in the shape of a circular disc of $50 \mathrm{~mm}$ diameter and 10 $\mathrm{mm}$ thickness. After partial drying in room temperature for 30 $\mathrm{h}$, the disc was removed carefully and heated at $120{ }^{\circ} \mathrm{C}$ for 14 $\mathrm{h}$. to the desired sintering temperature and kept in this temperature for $8 \mathrm{~h}$. Then, the temperature of the muffle furnace was cooled gradually to room temperature. . Membranes were prepared at four different sintering temperatures of $500{ }^{\circ} \mathrm{C}, 600{ }^{\circ} \mathrm{C} 7000 \mathrm{c}$ and $800{ }^{\circ} \mathrm{C}$.

Table.1: Composition of membranes

\begin{tabular}{|l|l|l|}
\hline Materials & Wet Basis & Dry Basis \\
\hline Clay (\%) & 58.26 & 85.81 \\
\hline $\begin{array}{l}\text { Sodium } \\
\text { Carbonate (\%) }\end{array}$ & 5.01 & 7.38 \\
\hline $\begin{array}{l}\text { Sodium Meta } \\
\text { Silicate (\%) }\end{array}$ & 2.40 & 3.54 \\
\hline Boric Acid (\%) & 2.20 & 3.252 \\
\hline Water (\%) & 32.10 & 0 \\
\hline
\end{tabular}

\subsection{Characterization}

Characterization was performed using SEM, Powder XRD, The membrane morphologies were observed via scanning electron microscopy (SEM, JEOL JSM-6480 LV) to determine average pore size and pore size distribution. Porosity. Prior to imaging, each sample was platinum coated in a specialized device to increase the conductivity for a better imaging. The synthesized samples were subjected to X-ray diffraction by a diffractometer (XRD, Philips Analytical, PW-3040) equipped with the graphite monochromatized $\mathrm{CuK} \alpha$ radiation $(\lambda=1.5406 \AA)$ in $2 \theta$ angles ranging from $20^{\circ}$ to $80^{\circ}$ with a step size of 2 degree and scanning rate 1 minute. Water permeation experiments were carried out to evaluate the average pore size and permeability. Chemical stability of the membranes was checked by comparing the porosity, pore size

\subsection{Water Permeability}

All membranes were subjected to water permeation experiments (Fig. 1) using deionized water. Hydraulic permeability (Lh) and average pore diameter (rl) were determined by the equation:

$$
J=\frac{n \pi r^{4} \Delta \mathrm{p}}{8 \mu l}=\mathrm{L}_{\mathrm{h}} \Delta \mathrm{p}
$$

Where, $\mathrm{J}$ is the liquid flux $\left(\mathrm{m}^{3} \mathrm{~m}^{-2} \mathrm{~s}^{-1}\right), \Delta \mathrm{P}$ is the transmembrane pressure $(\mathrm{kPa}), \mu$ is the viscosity of water, and 1 the pore length (i.e. thickness of membrane, assuming the pores are cylindrical). Taking porosity, $\varepsilon=$ (saturated wt-dry wt) /saturated wt Eq. (1) can be changed to:

$$
\mathrm{r}_{l}=\sqrt{\left[\frac{8 \mu l \mathrm{Lh}}{\varepsilon}\right]}
$$

The porosity was figured out by simple pycnometric method using water as a wetting liquid. The Trans membrane pressure drop for these experiments was in the range of $10-325 \mathrm{kPa}$. Before the experiment, standard compaction tests were conducted at a pressure of $300 \mathrm{kPa}$ which was above the operating pressure. The flux was initially high and reduced to a steady value. These data was taken by measuring the permeate of $300 \mathrm{ml}$ volume. In the next stage of the experiment, the flux through the membrane was measured with respect to $280 \mathrm{kpa}$ pressures. The hydraulic permeability (Lh) was obtained by Eq. (1). With this value and porosity value, the average pore radius was calculated by eq (2). 


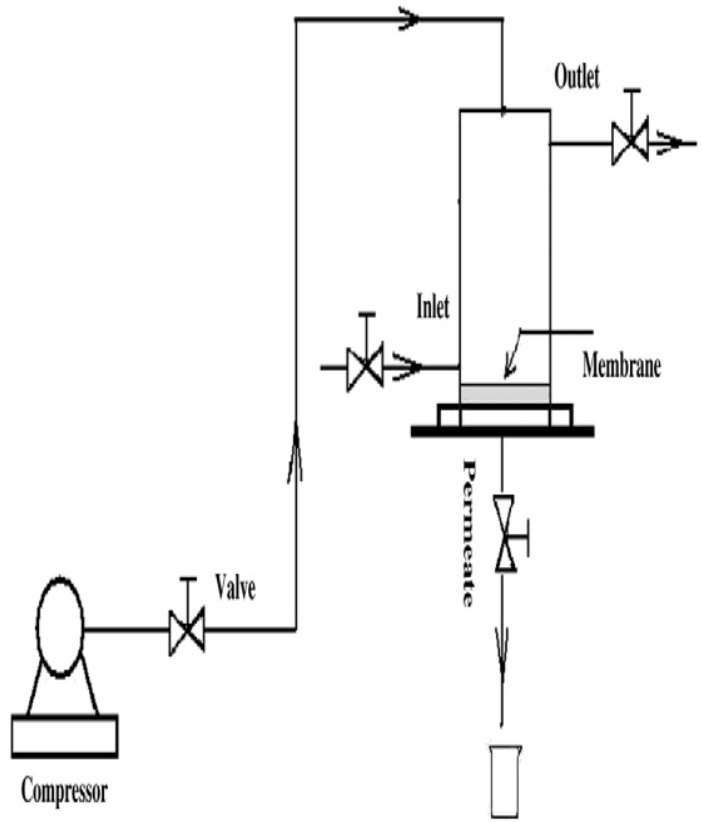

Fig.1: Experimental setup used for water permeation

\section{RESULTS AND DISCUSSION}

\subsection{X-ray Diffraction Analysis}

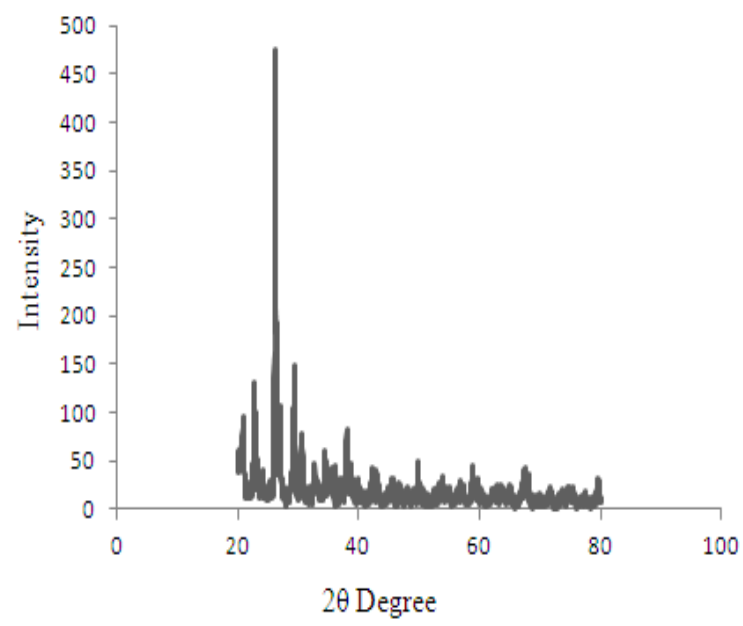

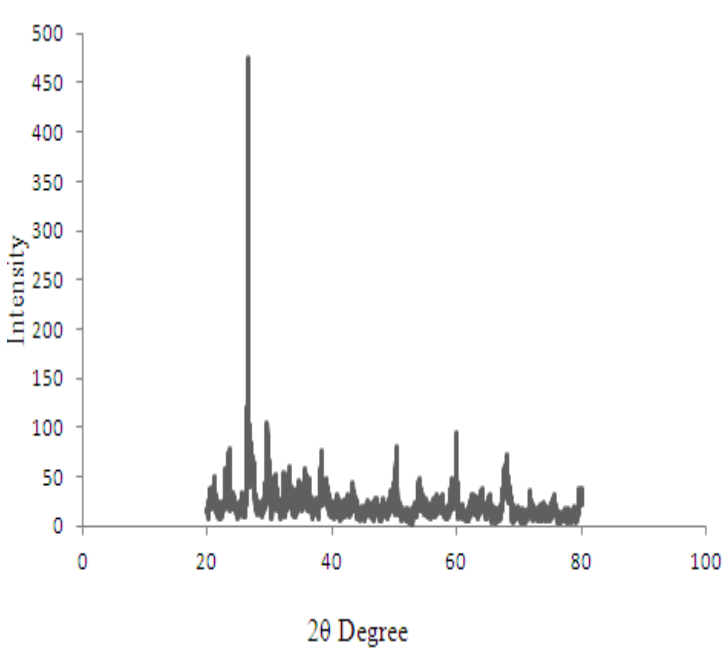

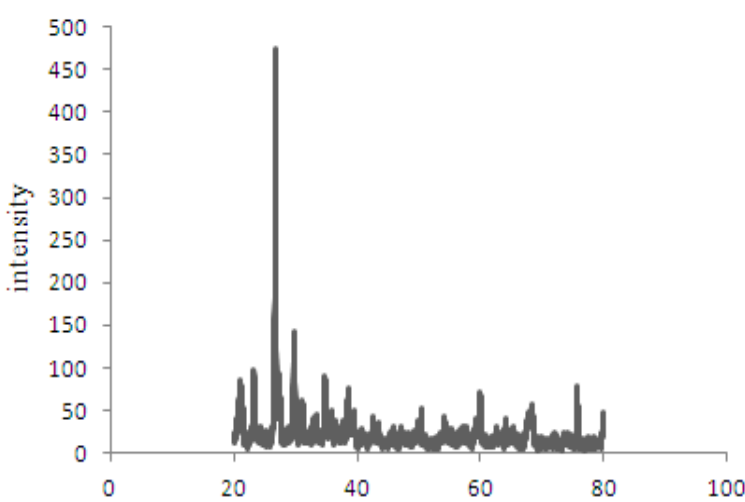

$2 \theta$ Degree

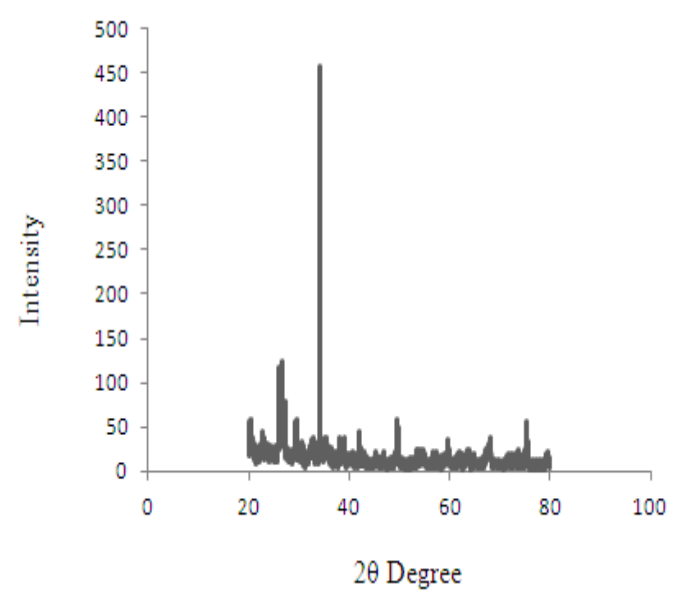

Fig.2: XRD analysis of the membrane $500^{\circ} \mathrm{c}, 600^{\circ} \mathrm{c}, 700^{\circ} \mathrm{c}$, $800^{\circ} \mathrm{c}$ 
From XRD analysis the compositions of membrane before sintering reflections of illite, kaolinite and quartz were observed from the literature. In the sintered samples, no reflection of kaolinite was found due to transformation to metakaolinite. For membrane at $500^{\circ} \mathrm{C}$ and $600{ }^{\circ} \mathrm{C}$, reflections of illite, mullite quartz and nephiline $\left(\mathrm{Na}_{2} \mathrm{O}, \mathrm{Al}_{2} \mathrm{O}_{3}, 2 \mathrm{SiO}_{2}\right)$ were found but at $800^{\circ} \mathrm{C}$ quartz. mullite and nephiline a reflection was detected. Quartz reflections did not change significantly. A critical observation of the peaks at higher temperature revels that there is significant phase transformation occurs at $800^{\circ} \mathrm{c}$. This signifies that the membrane skeletal structure constitutes mainly metakaolinite, quartz and nephiline . from the XRD analysis it all so can be concluded that the sintering temperature of $800^{\circ} \mathrm{c}$ is sufficient for membrane fabrication . all XRD diffraction graphs indicate no change in the peak trends corresponding to quartz thereby inferring that quartz phase is not at all affected by sintering of inorganic materials within the temperature consider in this work . therefore the sintering temperature up to $800^{\circ} \mathrm{c}$ considered in this work.

The major constituents of clay is from literature, silica in the form of silicon dioxide $\left(\mathrm{SiO}_{2}\right)$, aluminium as aluminium oxide $\left(\mathrm{Al}_{2} \mathrm{O}_{3}\right)$ and sodium as sodium oxide $\left(\mathrm{Na}_{2} \mathrm{O}\right)$. but after sintering the membranes contents mullite, kaolinite . illite, quartz, nephiline these spectrum obtained from X-ray diffraction analysis of sample shown above fig. 2 the XRD spectrum is matched with the JCPDs data base file (PDF-01-089-6538) wich indicate the above materials

\subsection{SEM Images}

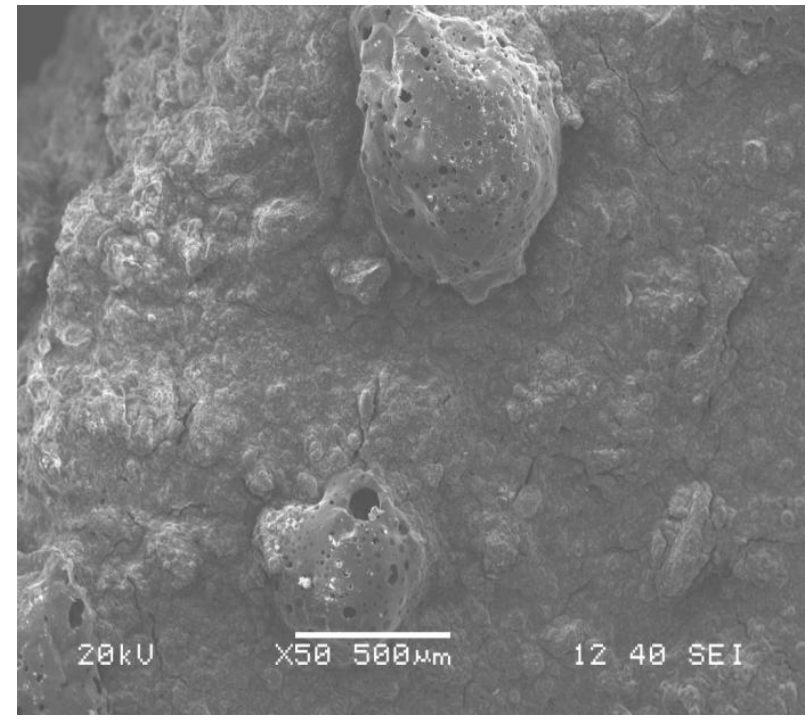

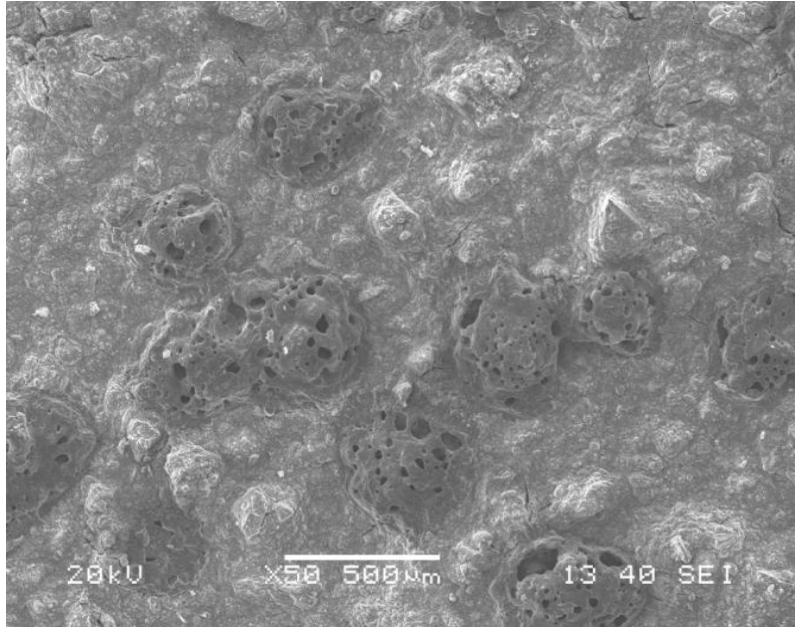
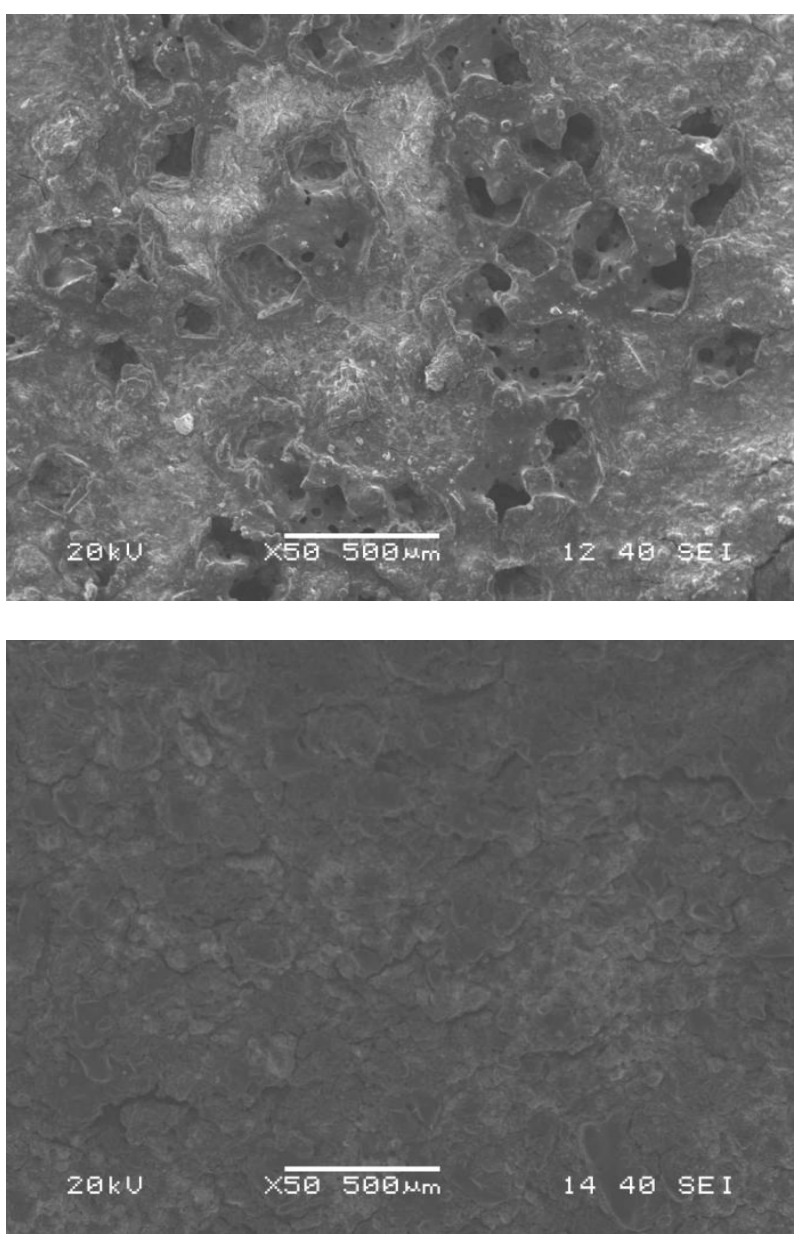

Fig.3: SEM images at $500^{\circ} \mathrm{C}, 600^{\circ} \mathrm{C}, 700^{\circ} \mathrm{C}, 800^{\circ} \mathrm{C}$

SEM pictures for the membrane sintered at four different temperatures considered in this work. All the membranes showed a surface with rough morphological structure. The ceramic substrates sintered at lower temperature shows highly porous structure. the membrane sintered at $800^{\circ} \mathrm{c}$ are more consolidated due to the fact that for sintering temperature over 
$750^{\circ} \mathrm{C}$ the particles agglomerate together creating more dense ceramic body. As a result the porosity of the membrane decreases with increase in sintering temperature (25-15\%). A superficial observation of the SEM indicates that the membrane did not have any pinholes cracks and the maximum observable pore size of the surface is about $12 \mu \mathrm{m}$

\subsection{Pore Size Distribution and Area Average Pore Diameter from SEM}

SEM images from different sections of the membrane were considered and around 500 pore diameters were measured using the ImageJ software. Average pore diameters (ds) were calculated by Eq. (3) where $n$ is the number of pores, and $d_{i}$ is the pore diameter $(\mu \mathrm{m})$ of the $\mathrm{i}$-th pore. The average pore size of membrane at $800^{\circ} \mathrm{C}$ is $5.68 \mu \mathrm{m}$. , the average pore diameter of membranes sintered at $500^{\circ} \mathrm{C}, 600^{\circ} \mathrm{C}, 700^{\circ} \mathrm{C}$ and $800^{\circ} \mathrm{C}$ was $2.26,3.43,4.93$ and $5.58 \mu \mathrm{m}$. The average pore size increased with the increasing sintering temperature. The reason was the overlapping of small pores creating large pores at higher sintering temperature.

$$
d s=\sqrt{\left[\frac{\sum_{i=1}^{n} n_{i} d_{i}}{\sum_{i=1}^{n} n_{i}}\right]}
$$

\subsection{Permeation Experiment}

he inorganic membranes are subjected to liquid permeation test using deionized water in batch mode operation. The hydraulic permeability, average pore diameter and porosity of the membrane are determined experimentally. Transmembrane pressure drop for water permeation test is maintain at 0250kpa (microfiltration range). Before using each fresh membrane, membrane compaction has been conducted using deionized water at a Transmembrane pressure 300kpa. During these experiments, the membrane flux was observed to be high initially and reduced to a steady state. At beginning flux of
$1.96 \times 10^{-5} \mathrm{~m}^{3} \mathrm{~m}^{-2} \mathrm{~s}$ which reaches to steady state value of $4.23 \times 10^{-5} \mathrm{~m}^{3} \mathrm{~m}^{-2} \mathrm{~s}$ shown in fig(4). These data was taken by measuring the permeate of $250 \mathrm{ml}$ volume. The hydraulic permeability and average pore radius of the membrane can be estimated according to the $\mathrm{Eq}(1)$. The average pore radius of the membrane is evaluated by assuming presence of cylindrical pores in the membrane matrix using the $\mathrm{Eq}$ (2). The porosity of the membrane is determined by pycnometric method using water as wetting liquid. The membrane porosity is decrease from $28 \%$ to $18 \%$ when sintering temperature varies from $500^{\circ} \mathrm{C}$ to $800^{\circ} \mathrm{C}$.this is due to the fact that increase in sintering temperature densification of the porous structure occur and thereby allow for an decrease in the membrane porosity.

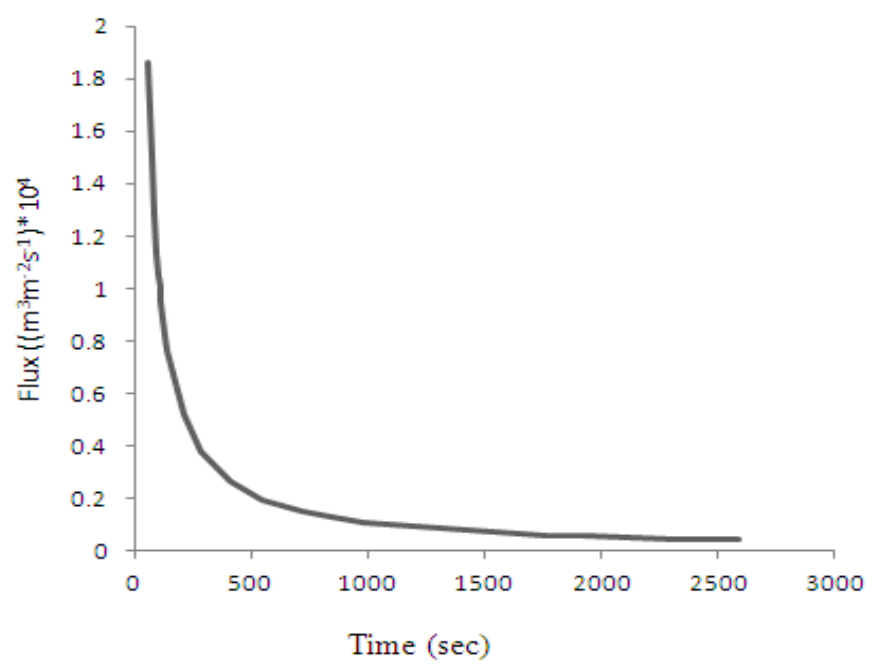

Fig.4. permeate flux

Table.1 Summary of crude oil-water emulsion separation using membrane

\begin{tabular}{|l|l|l|l|l|l|}
\hline S1. No & $\begin{array}{l}\text { Volume of } \\
\text { Permeate }\left(\mathbf{m}^{\mathbf{3}}\right)\end{array}$ & Time Taken (Sec) & $\begin{array}{l}\text { Area of } \\
\text { Membrane } \\
\left(\mathbf{m}^{\mathbf{2}}\right)\end{array}$ & $\begin{array}{l}\text { Flux } \\
\left(\mathbf{m}^{\mathbf{3}} \mathbf{m}^{-\mathbf{2}} \mathbf{s}^{-\mathbf{1}}\right)\end{array}$ & Rejection \% \\
\hline 1 & $1 \times 10-5$ & 752.14 & 0.002317 & $5.59424 \times 10-06$ & 32.23 \\
\hline 2 & $2 \times 10-5$ & 915.6 & 0.002317 & $9.1942 \times 10-06$ & 36.83 \\
\hline 3 & $3 \times 10-5$ & 1169.4 & 0.002317 & $1.07998 \times 10-06$ & 40.23 \\
\hline
\end{tabular}

\subsection{Separation of Crude Oil from Crude Oil-Water}

\section{Emulsion}

A brief overview of results on rejection of crude oil is summarized in the Table 6Here; we report a rejection percentage of approximately $52.32 \%$ for crude from oil-water emulsion system. As indicated, cumulative rejection \% increases as time of process increases. This is mainly attributed to blockage of larger pores by oil emulsion and formation of oil slick. Blockage of pores by the oil slick also causes increase in pressure drop across the membrane. However, higher operating pressure is not recommended for 
this micro-filtration system. Literature also reports the gradual reduction of flux with an increased oil concentration. This is due to increase in the adsorptive and concentration polarization resistances because of higher feed concentration. We also observed that size of oil droplet and initial oil concentration in the emulsion system is also an important factor that determines the rejection percentage. An increase in oil rejection up to $85 \%$ with simultaneous decrease in flux is reported elsewhere [10] However for the operating pressure of $300 \mathrm{kPa}$, they obtained rejection of $44 \%$ (This work reports a rejection of $52.32 \%$ for $275 \mathrm{kPa}$ ). The coalescence and wetting of oil droplets with increased pressure force oil drops through the membrane pores is the reason for decreased rejection percentage.

\section{CONCLUSIONS}

Microfiltration membranes were prepared from locally available clay collected from NIT Rourkela campus. The study indicates that with the addition of a small amount of sodium carbonate, sodium metasilicate and boric acid, a high flux ceramic microfiltration membrane can be prepared. This study indicates that a defect-free ceramic membrane can be fabricated with high content of red mud and low content of expensive precursors. The thermal characterization and XRD study inferred that the appropriate sintering temperature for the chosen composition of membrane is 8000C. The observable maximum pore size of the membrane is $6 \mu \mathrm{m}$. the distribution of pore size based on SEM and physical interpretation is good and only $28-18 \%$ of porous structure contribution towards the transport studies. The approximate cost of the membrane fabricated is cheaper than commercially available ceramic membranes and compare well with other reported cost data. These results provide significant opportunity to develop ceramic micro-filtration membranes with flexible pore sizes for industrial application. Separation of crude oil from crude oil-water emulsion using membrane is 53.23 (\% Rejection).

\section{REFERENCES}

[1]. Nandi B.K., Uppaluri R., Purkait M.K. Preparation and characterization of low cost ceramic membranes for microfiltration applications, Applied Clay Science 42 (2008): pp. $102-110$

[2]. Somen jana, Purkait M.K , Mohanty.K . Preparation and characterization of low cost ceramic microfilteration membranes for the removal of chromate from aqueous solution.Apllied Clay Science 47 (2010): pp. 317-324

[3]. Jana S., Saikia A., Purkait M.K., Mohanty K. Chitosan based ceramic Ultrafiltration membrane: Preparation, characterization and application to remove $\mathrm{Hg}$ (II) and $\mathrm{As}$ (III) using polymer enhanced, Chemical Engineering Journal 170 (2011): pp. 209-219

[4]. Khemakhema*, A. Larbotb, R. Ben Amar. Study of performances of ceramic microfiltration membrane from
Tunisian clay applied to cuttlefish effluents treatment. Desalination: pp 200 (2006) 307-309

[5]. L. Palacioa, Y. Bouzerdib, M. Ouammoub. Ceramic membranes from Moroccan natural clay and phosphate for industrial water treatment Desalination 246 (2009) : pp 128134

[6]. K. Li, Ceramic Membranes for Separation and Reaction, John Wiley \& Sons, Inc., England.2007.

[7]. B.K. Nandi, B. Das, R. Uppaluri *, M.K. Purkait. Microfiltration of mosambi juice using low cost ceramic membrane Journal of Food Engineering 95 (2009) 597-605

[8]. D. Vasanth, G. Pugazhenthi*, R. Uppaluri. Fabrication and properties of low cost ceramic microfiltration membranes for separation of oil and bacteria from its solution Journal of Membrane Science 379 (2011) 154- 163

[9]. V. Jegatheesana,D.D. Phonga,L. Shua, R. Ben Aim "Performance of ceramic micro- and ultrafiltration membranes treating limed and partially clarified sugar cane juice" Journal of Membrane Science 327 (2009) 69-77.

[10]. R.J. Steindl and D.W. Rackemann "Membrane filtration of clarified juice” Proc. Int. Soc. Sugar Cane Technol., Vol. $27,2010$.

[11]. V. Jegatheesan, L. Shu, G. Keir, D. D. Phong "Evaluating membrane technology for clarification of sugarcane juice" Rev Environ SciBiotechnol (2012) 11:109124.

[12]. M.J. Um, S.H. Yoon, C.H. Lee, K.Y. Chung, K.Y. Kim, "Flux enhancement with gas injection in crossflow ultrafiltration of oily wastewater" Water Res. 35 (2001) 40954101.

[13]. A. El-Kayar, M. Hussein, "Removal of oil from stable oil-water emulsion by induced air floatation technique" Sep. Technol. 3 (1993) 25-31.

[14]. A.Y. Hosny, "Separating oil from oil-water emulsions by electroflotation technique" Sep. Technol. 6 (1996) 9-1.7 